\title{
EMERGENCE OF NEW TECHNOLOGY: EXPLORING THE POTENTIAL OF ARTIFICIAL INTELLIGENCE IN EDUCATION
}

\author{
KAJAL ROY, B.Sc., MBA (Ph.D.) ${ }^{1},{ }^{\text {DR }}$ \& NOOR FIRDOOS JAHAN, Ph.D² \\ ${ }^{1}$ Research Scholar, ISBR Research Centre, University of Mysore, India. \\ ${ }^{2}$ Professor, R. V. Institute of Management, Bengaluru, India
}

\begin{abstract}
Artificial Intelligence has created a revolution in every field of our life. The advent and emergence of Artificial Intelligence has helped us improve the efficiency of our work. Artificial intelligence has taken our smart intelligence and computing capabilities to much superior heights. Artificial Intelligence comes up with smart ideas to enhance human intelligence. This paper examines the role of Artificial Intelligence and how it will impact various functioning of higher education, to understand the potential of Artificial Intelligence in education. This paper studies how Artificial Intelligence impact teaching learning process, the way students learn, change in methodology, implication of new technologies of Artificial Intelligence, teaching process, evaluation, growth, automation of administrative task and importance of AI based tools and learning during pandemic. Recent technological advancements during the pandemic situation and the sudden need for innovation and adopting AI/ML in higher education are studied. Post Covid era Artificial intelligence will be part of institutions, universities and education worldwide and transformation in education process.
\end{abstract}

This paper also brings up the challenges faced by students, administration, faculties and institutions of higher education in the adoption of AI and technologies for teaching learning process.

KEYWORDS: AI, ML, Artificial Intelligence, Technology, Innovation, Higher Education, Learning, Education System

Received: Aug 04, 2020; Accepted: Aug 24, 2020; Published: Nov 21, 2020; Paper Id.: IJESRAUG202018

\section{INTRODUCTION}

Education is a system and a process of facilitating learning, education can also be perceived as an art of teaching, science, as an act by which knowledge is imparted.

The education system and higher education is closely linked with the new systems, technologies, computer-based intelligence, machine learning, and technological developments. Artificial Intelligence has emerged and opened various avenues in every field including education.

In this article an attempt has seen made to identify the Goals of Education, its function, drawbacks and study the applications of AI its impact on these Goals of Education. It is important to note that current state of Education in India is under transition and Schools, Colleges and Universities are willing to change, adopt various new innovation, best practices and follow the world's top practices. The main purpose of this paper is to critically examine the role Artificial Intelligence will play on education and on the teachers, learners of higher Educational Institutes. 


\section{What is Artificial Intelligence?}

Definition of Artificial Intelligence is constantly changing, in such a scenario it becomes difficult even for the experts to define Artificial Intelligence (AI). Nick Bostrom, an Artificial Intelligence expert from Oxford University explains: “[a] lot of cutting-edge AI has filtered into general applications, often without being called AI because once something becomes useful enough and common enough it is not labelled AI anymore."

The term “Artificial Intelligence" was first phrased in 1956 by John McCarthy of the University of Massachusetts after that a huge number of definitions were proposed. Some definitions are listed here

McCarthy explained Artificial Intelligence as "It is the science and engineering of making intelligent machines, especially intelligent computer programs."

Merriam-Webster defined AI as "A branch of computer science dealing with the simulation of intelligent behaviour in computers."

Dictionary.com defined Artificial Intelligence as "The capacity of a computer to perform operations analogous to learning and decision making in humans"

Microsoft Corporation defined it as "The ability to learn facts and skills and apply them". These definitions give a fair idea about what Artificial Intelligence deals with and covers.

\section{Types of AI}

Artificial Intelligence has been categorised into various types. There are various different approaches to AI and they are categorized based on their different approaches like Data based, Skill based, Logic based, Task based and Knowledge based.

Data based Artificial intelligence is in huge demand because big data is very difficult to manage without AI. AI helps to store data and knowledge which can be used in predictions based on likings, dislikes, recommendations, reference etc. which are mostly used by the ecommerce sites. AI algorithms work brilliantly with data analytics. Big Data is here to stay and is the future of the analytics so is AI. Data and AI has to work in synergy.

Skill based AI - AI is totally based on algorithms and mathematical knowledge, it is totally logical and analytical skill based. AI programmes deals with huge data sets which requires efficient skills of distributed computing.

Logic based AI - In 1959 John McCarthy stated the importance of mathematical logic for Artificial intelligence. The book Logic-Based Artificial intelligence by Jack Minker mentioned about computational logic, co-relation between logic, probability and decision making in AI. Logic for causation and actions.

Task based AI - Task based interactions and assistance virtually offer benefits with respect to social, cognitive, behavioural intent. Task based design approach offers larger flexibility and modularization.

Knowledge based AI - Knowledge based configuration for AI applications is one of the most successful model as explained by expert systems. In spite of significant progress in the field of AI there are various technical challenges to overcome. 


\section{RESEARCH OBJECTIVES}

- To study the role of Artificial Intelligence and its impact on various functioning of Higher Education.

- To study the challenges encountered by the institutions of Higher Education in adopting AI and technology-based learning.

\section{RESEARCH METHODOLOGY}

Exploratory Research is adopted for this study. Both primary and secondary data is considered for this study. Primary data is collected through online interaction with the business heads, experts and secondary data is collected with the help of various books, journals, articles, research papers, web source etc. for this study and from various sources of literature on digital technologies are also explored. Some sectors selected for the study are health care, education, manufacturing, mobility and retailing.

\section{LIMITATIONS OF THE STUDY}

- There was limited time period for conducting the study, hence restricted the scope for a detailed research

- Respondents were from various institutions of Higher Education due to which the research may not be able to suggest specific AI strategy based on one education stream.

\section{FINDINGS AND DISCUSSIONS}

Technology can help transform how we teach and learn While many sectors have been disrupted by technology and adopted advance technology, higher education has remained focused to its traditional format of imparting knowledge. However slight technological transformation had started in the higher education by various universities. During the current challenges and under pandemic situation the universities, colleges and institutions are using - AI, big data, machine learning, block chain, AR VR applications to deliver online learning. The pandemic has transformed the total education system of imparting knowledge, teaching - learning process all together, perhaps this pandemic is the time to take a deeper view of how education could innovate and transform itself technically. Faculty and academic throughout the world are working round the corner to transfer the learning material, do online teaching and assessment by using various AI based tools and technologies.

AI technologies and various AI educational models like Learner model, Pedagogical model, and Domain model are used in AI to improve educational system and better knowledge assessment and deliver. Deep learning, machine learning and NLP (Natural language processing) are been used for better remote teaching learning experience.

By markets and merkets.com, it is projected that the global AI in education market to reach USD 3.68 billion by 2023, at a CAGR of 47\% during the forecast period 2018 till 2023. 


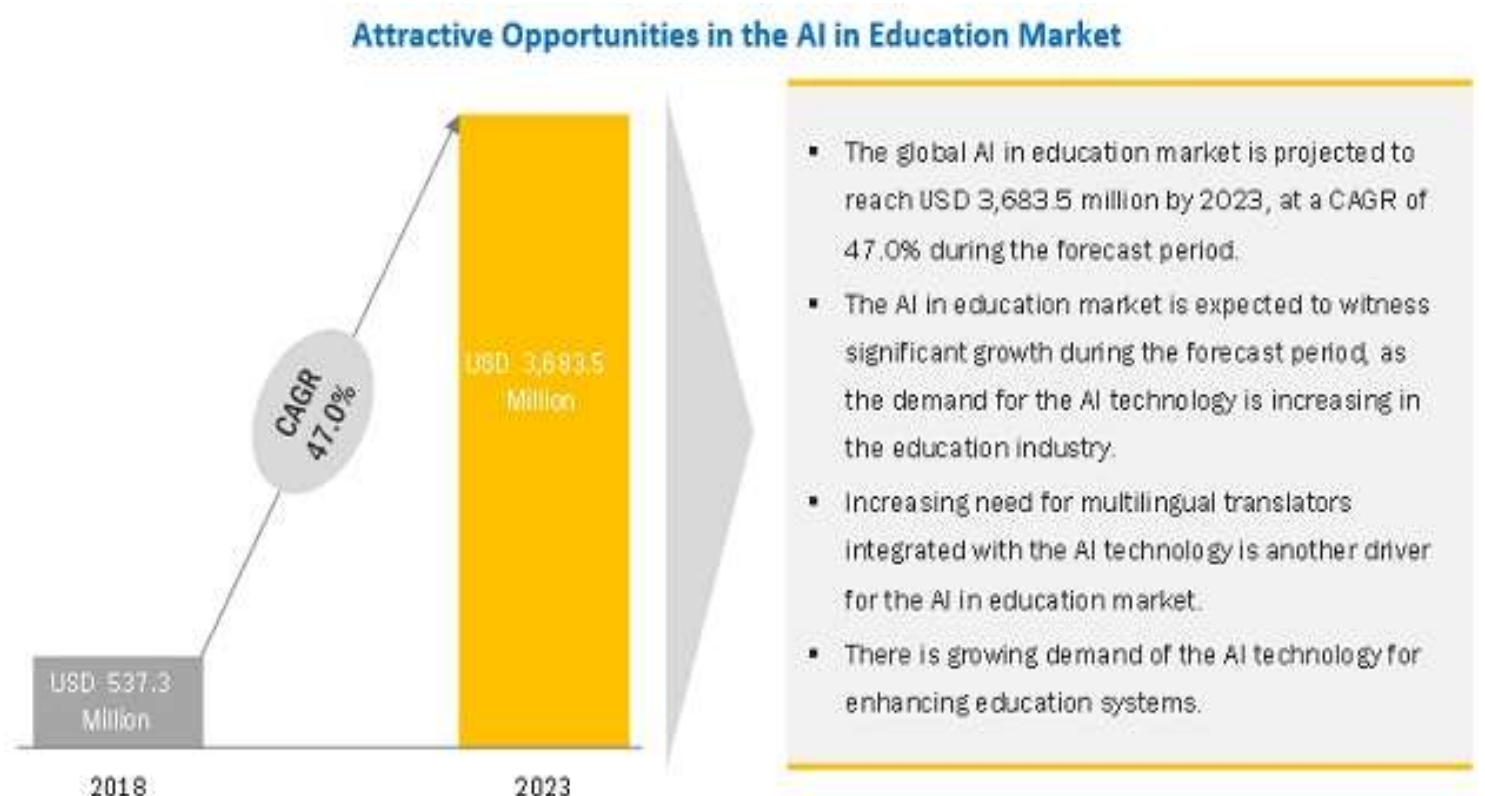

Source: marketsandmarkets.com

The virtual facilitator, AI and learning applications by 2023 are projected to have largest market size. AI based technology include knowledge delivery, academic mapping, planning of students, student's administration and engagement, most important real time communication and interaction. Real time data, AI, ML and a range of new devices and tools will help transform the roles of students, teachers and parents.

\section{ARTIFICIAL INTELLIGENCE (AI) AND EDUCATION}

Most of the studies on AI and education have been done in US and other countries. Not much research or impact of AI in Education has been studied in India. AI has recently attracted huge attention and huge potential is seen and felt in every sector including Education.

The quality of education has high potential of improvement with the use of technology-based AI educational tools. AI allows computers to take decision and perform from simplest to complex task with efficiency within no time which requires human intelligence to do it.

Various applications of AI in higher education, administration and classroom, whether remote for face to face can integrate Artificial Intelligence for teaching, administrations and evaluation process. These AI based applications are mainly used to enhance and augment the faculties and administrative capabilities.

\section{GOALS OF EDUCATION}

The aim of this paper is to explore the impact of applications of AI on current and future higher educational system. David Perkins' 1992 book analysed and listed goals of education and suggested improvements on how these goals of education can be accomplished (Perkins, 1992, p5):

- The first goal of education is imparting knowledge and skills which can be retained by the pupils.

- The second goal of education is having an understanding of the skills and knowledge acquires during the learning process. 
- The third most important goal of education is application of the skills and knowledge acquired. Once the knowledge is retained the students should be able to apply it, develop the analysing ability and use the knowledge.

These three major goals of education primarily guide the formal education system throughout the world. These goals of education are accepted throughout the world over the years. This sets a strong foundation helps in analysing the existing system and propose a futuristic educational system.

Perkins' three goals does not pin point any specific or particular board of education, curriculum, syllabus, content, administrative processes, record tracking, record /data analysis student's enrolment, assessment, evaluation, teacher's/ staff reports or any other aspect of education system. The three goals of education mentioned are general in nature and is useful in discussion about IT, communication, Artificial Intelligence and change required in education system.

The TABLE below discusses goals of education, its functions, drawbacks and impact of Artificial Intelligence on these goals.

Table 1: Goals of Education and Impact of Artificial Intelligence on these goals

\begin{tabular}{|c|c|c|c|}
\hline Goals of Education & Functions & Drawbacks & Impact of Artificial Intelligence \\
\hline $\begin{array}{l}\text { 1. First goal of } \\
\text { education imparting } \\
\text { knowledge and skills } \\
\text { which can be retained }\end{array}$ & $\begin{array}{l}\text { Education system } \\
\text { today can be } \\
\text { described } \\
\text { "memorize, as } \\
\text { regurgitate, and } \\
\text { forget." }\end{array}$ & $\begin{array}{lr}\text { This is } & \text { rote } \\
\text { memorization } & \text { approach } \\
\text { to learning } & \end{array}$ & $\begin{array}{l}\text { Technology can be very useful in storage, } \\
\text { retrieving information. Use of computers and } \\
\text { technology can be very effective in storage of } \\
\text { knowledge and information and retrieving } \\
\text { them in no time. }\end{array}$ \\
\hline $\begin{array}{l}\text { 2. The second goal of } \\
\text { education is } \\
\text { Understanding of } \\
\text { acquired knowledge } \\
\text { and skills }\end{array}$ & $\begin{array}{l}\text { Understanding } \\
\text { mainly deals with } \\
\text { data, knowledge, } \\
\text { information, } \\
\text { understanding and } \\
\text { wisdom. }\end{array}$ & $\begin{array}{l}\text { Understanding varies } \\
\text { from person to person, } \\
\text { institute to institute based } \\
\text { on knowledge and skill } \\
\text { sets. }\end{array}$ & $\begin{array}{l}\text { A computer is a machine which has input, } \\
\text { storage, memory, arithmetic logical unit, } \\
\text { algorithm manipulation, output of data and } \\
\text { information. } \\
\text { But what about knowledge?? } \\
\text { AI Plays a key role here. Technology and } \\
\text { computers are mainly used for "knowledge } \\
\text { management." It processes huge data and } \\
\text { information in order to produce and derive } \\
\text { knowledge. }\end{array}$ \\
\hline $\begin{array}{l}\text { 3. The third goal of } \\
\text { Education is active } \\
\text { use of one's acquired } \\
\text { knowledge and skills }\end{array}$ & $\begin{array}{l}\text { One of the major } \\
\text { goals in education } \\
\text { is transfer of } \\
\text { knowledge and } \\
\text { skills acquired from } \\
\text { classroom set up }\end{array}$ & $\begin{array}{l}\text { Students should be able } \\
\text { to use their school- } \\
\text { acquired knowledge and } \\
\text { skills at home, work, } \\
\text { play, outside } \\
\text { environment. }\end{array}$ & $\begin{array}{l}\text { A well-designed "Intelligent" Computer } \\
\text { Assisted Learning system engages students } \\
\text { and learners in interactions in which the } \\
\text { student can immediately apply knowledge } \\
\text { gained, learned and studied in the classroom } \\
\text { environment. }\end{array}$ \\
\hline
\end{tabular}




\begin{tabular}{|l|l|l|l|}
\hline & $\begin{array}{l}\text { learning to general } \\
\text { application in } \\
\text { another } \\
\text { environment. }\end{array}$ & $\begin{array}{l}\text { An example for the same is the "Help" tool } \\
\text { which is a prime feature of computer-based } \\
\text { application. Help tool makes use of AI, it } \\
\text { stores information which can be precisely } \\
\text { retrieved at any time. }\end{array}$ \\
\hline
\end{tabular}

Source - Complied by Researcher

\section{IMPACT ON LEARNING, TEACHING AND EDUCATION}

Impact of AI can be identified on the following level

- $\quad$ Awareness and readiness to accept AI

- Perception of the faculty, management, staff and students towards the applications

- Sustainability and upgradation of the current infrastructure and process:

- Upgradation and modification of the present management process (e.g. admission procedure, data collection and analysis, placement etc.)

- Implementation of AI and computer-based education conversion and transformation of the system (e.g. digital learning, online learning, automated system, mobile learning).

- Impact on research, innovation and consultancy of education.

\section{POTENTIAL IMPACT OF AI ON TEACHERS}

\section{Few functions where AI can make impact in Teachers and Learners in Higher Education are}

- Automated Grading system, Artificial Intelligence based assessments using mathematical model, compute algorithms and statistical methods that fit network to construct data. This can save a huge mechanical routine time of teachers.

- Virtual Lecture and learning system. Higher Education can easily of Virtual Lecture and learning system. Many Universities in US and also to some extent in India has started adopting Virtual learning system in Higher Education. University of South California, institute of Creative Technologies develop smart visual environment.

- Connecting the world of academia, the world of academia can be easily connected with the help of AI, saving millions of administrative cost.

- Addition of smart content, digitalised curriculum, text books and create user interface. Cram101 uses AI to condense the content in the text books into a more digestible study guide. Digital learning allows academia and authors to design e- curriculum and content which can save huge hard copy text book printing cost.

- -Smart Tutors and Personalisation. Carnegie uses data from students. AI application is still in early stages of development here as there are various privacy concerns and data safety involved here.

- Admission procedure, Data accumulation and personalisation can be easily automated by AI system.

- Teaching and learning procedure, student teacher management and relationship, student teacher administrative support system and management. 
- Placements, Students feedback loop and Alumni management

- Research, consultancy and innovation.

Artificial Intelligence can be effectively used and applied on various functions of teaching learning process; we have seen tremendous transformation in education system during pandemic. Every e-based platform and digital learning tool is AI based. It has totally transformed education system across the globe, it is more effectively used for the higher education and enhances self-learning skills.

\section{CHALLENGES FOR ARTIFICIAL INTELLIGENCE IN EDUCATION}

- AI will replace people. The greatest challenge is the perception that Artificial Intelligence will replace people with machines. Teachers and faculty have the fear that soon classroom teaching will be history and their role will not be require with the use of Artificial Intelligence and computer based technologies for teaching. But we must admit that even with the tremendous transformation of teaching during pandemic with complete change over from class room teaching to online mode and digital learning faculty is required. There is limitation to technology, human interface is required.

- Student Privacy. Like any other digital services, AI-enabled education tools collect and store personal information. There needs to be policy of security measure of stored data and student privacy maintained. There is a fear among parents and students of misuse of students' data and selling of data.

- Product Procurement and Support. Choosing Artificial Intelligent enabled product and software, hardware requires expertise and can be a tiresome effort for the procurement team to understand the product, its features, whether it meets the requirement of the teachers, management staff and students, its effectiveness for the institute. Should involve the staff, teachers, IT admin, management, students from the beginning of the process of the procurement, which is an extensive and time-consuming task. While some institutes allow open involvement, some do not. Depending upon the finance and budget they often appoint a consultant for guidance in selecting the correct AI tool.

- Accountability. Mistrust can come because most of the IT and software companies refuse to disclose their algorithms, considering the high competition in this field, they argue that such algorithms are trade secrets. Parents, students and staff may not trust the AI tool to make decisions of student's learning.

- Virtual Learning - "Students learn from their teachers, not from electronic gadgets." was an old statement. This pandemic has brought a total transformation into the mode of learning and brought in total changeover into virtual learning and online teaching. However there are many challenges of virtual learning, some of them are lack of in-person interaction, learning style, over influence of electronic devices, adjusting to the new technology, technical upgradation, technical issues, understanding syllabus and course expectation, online distractions, online assignment completion, online evaluation challenges to name a few.

- Practical hands on learning not possible through Virtual mode. - Where technical knowledge of learning through practical is involved students cannot learn through Virtual mode, mainly in the stream of Science, Technology where experiments has to be performed in laboratories, medical science, engineering, chemical experiments cannot be done through virtual mode of learning. 


\section{SUGGESTIONS}

Artificial Intelligence is the future in every aspect of human life. There might be some above mentioned challenges which needs to be overcome for the successful implementation of applications of AI in Education. Teaching faculty and academia should not have the fear of been replaced by a machine. AI is to enhance their performance and make ease of their daily routine mechanical work.

Regarding privacy of the students and learners data, system needs to be full proof, advance level security and fireworks required for data security.

Product and Support should be more user-friendly and should not require special learning or expertise to understand the features of the AI products.

Accountability and trust can be developed with time and use of AI product and service. IT and software companies need to relax their policies and try to build up trust among parents, students, teachers and administrative staff of colleges and universities.

Challenge regarding Virtual Learning, a teacher's importance in education cannot be undermined however virtual learning can be useful for students residing in remote locations who have no access to higher education and teachers. Also Virtual Leaning is beneficial when addressing huge audience who might not be residing at one location. International seminars and conference can be conducted for the benefits of global students and learners. And above all learning has continued during this pandemic due to virtual and digital mode of online teaching and learning. Not only teaching learning but various FDP's, seminars, paper presentations has happened across globe through webinars and e-conference which was possible only because of AI tools and its applications.

\section{CONCLUSIONS}

Indian Education needs effective AI system. AI based applications can provide effective solutions for institutes, administrative task of record monitoring, admission, projections, data accumulation, personalisation, alumina tracking and management, and various other administrative services. AI solutions have been rigorously used during the pandemic for virtual teaching and online classes. AI applications and solutions offer numerous possibilities for virtual teaching and learning in education. However, it presents a lot of challenges too. There is a fear of technology replacing faculty and staff members. But the present technology and AI tools require human interface and it is important to admit the limitations of technology is not yet ready to replace teachers, faculty and administrative staffs.

Education, teaching and learning is human centric and not technology centric, solutions of AI and technology can enhance efficiency, effectiveness of teachers, management and staff and open new possibilities in education. However, with the advancement and influence of technology, the idea of solely relying on technology is risky and not feasible for education. Education is primarily human centric and machine cannot take over completely, human should identify the teaching process, control requirements, provide solutions with main focus on teaching- learning process and knowledge impartment.

The real and ideal potential of software technology and Artificial Intelligence is when used to enhance efficiency and capabilities of human. 


\section{REFERENCES}

1. The Oxford dictionary of English (Oxford dictionaries online). Oxford: Oxford University Press. AND Russell, S. J., Norvig, P., \& Davis, E. Artificial intelligence: A modern approach. Upper Saddle River: Prentice Hall.

2. Ron Glatter, Lesley Kydd First Published July 1, 2003 Best Practice' in Educational Leadership and Management Abstract Volume: 31 issue: 3, page(s): 231-243 Issue published: July 1, 2003

3. Peter Serdyukov, (2017) "Innovation in education: what works, what doesn't, and what to do about it?", Journal of Research in Innovative Teaching \& Learning, Vol. 10 Issue: 1, pp.4-33

4. Avery Phillips (May 2018) - in her article The Future of AI and Education

5. Jonathan Wolpaw and Elizabeth Winter Wolpaw, (2012) - Brain Computer Interfaces: Principles and Practice.

6. Russell, Stuart J and Norvig ,Peter (2016)- Artificial Intelligence : A Modern Approach

7. Sian Bayne (2015) Teacherbot: interventions in automated teaching.

8. U.S. National Science and Technology Council (2016). National Artificial Intelligence Research and development strategic plan.

9. J. Liebowitz (2001) (Book) Expert Systems with Applications, Volume 20, Issue 1, January 2001, Pages 2-16,. 'Knowledge management and its link to artificial intelligence "

10. Jaime R. Carbonell (1970) IEEE Transactions on Man-Machine Systems (Volume: 11, Issue: 4, Dec. 1970) AI in CAI: An Artificial-Intelligence Approach to Computer-Assisted Instruction

11. Fedor Klashanov (2016) (Book), Procedia Engineering Volume 165, 2016 Pages 1016-1020. 'Artificial Intelligence and Organizing Decision in Construction,"

12. Lisa A Petrides and Susan Guiney (2002), Teachers college record Volume 104, number 8, December 2002, Knowledge Management for School leader: An ecological Framework for thinking schools.

13. Robert Neches, Richard E. Fikes, Tim Finin, Thomas Gruber, Ramesh Patil, Ted Senator, William R. Swartout (1991) (Book), Vol 12, No3: Fall 1991, 'Enabling Technology for Knowledge Sharing'”

14. Karl Utermohlem (2018), 4 ways AI is changing the Education Industry

15. Shuxia Wang (2016) Vol13, No5, Research on the Teaching Reform of college Students' Entrepreneurship Education Combined with Artificial Intelligence.

16. R. Luckin, W. Holmes, M. Griffiths and L. B. Forcier, "Intelligence Unleashed: An Argument For AI In Education,"

17. J. Self, (1998) “The Defining Characteristics of Intelligent Tutoring Systems Research: ITSs Care, Precisely,” International Journal of Artificial Intelligence in Education (I J ARTIFICIAL INTELLIGENCE IN B-SCHOOL EDUCATION), vol. 10, pp. 350-364, 1998.

18. Nwulu Evarista and Nahum Homti,(2015) 'Artificial Intelligence - Now and the Future ' International Journal of Computer Applications (0975 - 8887) Volume 114 - No. 18, March 2015

19. Dimitrova, V., Mccalla, G., Bull, S. (2007). Preface: “Open Learner Models: Future Research Directions". International Journal of Artificial Intelligence in Education.

20. Du Boulay, B., Rebolledo-Mendez, G., Luckin, R., Martínez-Mirón, E., \& Harris, A. (2007). “Motivationally Intelligent Systems: Diagnosis and Feedback". 
21. Dweck, C. S. (2010). “Even Geniuses Work Hard”. Educational Leadership. 68(1), 16-20.

22. Joyce J. Lu and Laurie A. Harris, L Harris (2018) "Artificial Intelligence (AI) and Education" Congressional Research service.

23. Vladan Devedzic (2004) Educational Technology \& Society 7(4):29-39 'Web Intelligence and Artificial Intelligence in Education",

24. Chandru Sharma (2019) 'Artificial Intelligence and Education' academia 2019.

25. Fullan, M., \& Donnelly, K. (2013). Alive in the swamp: Assessing digital innovations in education. London: Nesta. 